\title{
Challenges of Internal and External Variables of Consumer Behaviour towards Mobile Commerce
}

\author{
Arif Sari ${ }^{1}$, Pelin Bayram² \\ ${ }^{1}$ Department of Management Information Systems, Girne American University, Kyrenia, Cyprus \\ ${ }^{2}$ Department of Business Management, Girne American University, Kyrenia, Cyprus \\ Email: arifsari@gau.edu.tr, pelinbayram@gau.edu.tr
}

Received 25 August 2015; accepted 15 September 2015; published 30 December 2015

Copyright (C) 2015 by authors and Scientific Research Publishing Inc.

This work is licensed under the Creative Commons Attribution International License (CC BY). http://creativecommons.org/licenses/by/4.0/

c) (i) Open Access

\section{Abstract}

The Mobile Commerce (m-commerce) becomes very powerful tool in the competitive business markets. Companies started to use this technology to attract their customers and catch their attention. Usage of Mobile commerce applications spreaded around different countries and became very popular. Different communication protocols and security techniques are designed for business use of $\mathbf{m}$-commerce. Mobile Commerce, likewise the e-commerce brought significant difference in the market. People start to use this technology by feeling the freedom of having transactions at anywhere and anytime. However, consumers face lot of difficulties while using this technology which is consumer-based or service provider based. This research exposes the impact of determinants that influences mobile commerce application users' attitudes by classifying and investigating the internal and external variables in a case study of Cyprus Research Centre.

\section{Keywords}

M-Commerce, Internal Variables, External Variables, Consumer Behaviour

\section{Introduction}

Technology never stops to advance, as our needs increase so those new innovations come up and easier ways for things to work that will bring about efficiency.

Mobile commerce (M-Commerce) like its grand-daughter of Electronic commerce, enhance business strategies and simultaneously make it easy for users to comply with. M-commerce involves the Electronic transactions between buyers and sellers using mobile communications devices such as cell phones, personal digital as- 
sistants (PDAs), or laptop computers (Miller, 2010). This form of commerce is flexible, highly mobile, and extremely versatile, making it a popular model for some businesses, including companies which only do business electronically as well as consumers in the public.

In many different countries, M-Commerce became very popular and powerful tool for communication and data exchange. People use this technology for private and corporate proposes. Different mobile commerce applications serve for different sectors. Today's technology savvy people appreciated for this technology because of its significant difference. It brought lot of advantages into our life from many different perspectives. Instead of music, video and chatting purposes, M-commerce brought significant difference for transactions at train stations, cinemas, parking places etc.

Payments, admissions to events, interactive services and information services such as weather forecasts, traffic information, exchange rates etc. are some of the advantages that mobile commerce provides to consumers at anytime and anywhere.

However, consumers face a lot of obstacles while using this technology. Consumer behaviour and attitudes towards mobile commerce change rapidly, because of several reasons which cause of these obstacles. These obstacles may be environmental, or consumer related. This study concentrated on the particular region and conducted a survey to analyze the consumer behaviour towards mobile commerce applications.

The paper is structured by discussing Mobile Commerce and Challenges of Mobile Commerce in section. Section 3 explains the relationship between M-Commerce and Challenges of M-Commerce with different subsections by covering customer loyalty and trust issues in M-commerce activities. The research model formulation, the hypothesis testing, sampling, data collection and questionnaire design are explained in Section 3. The findings of the research are exposed in Section 4 with different frequencies. Section 5 elaborates the results of hypothesis testing and concluding the research.

\section{Mobile Commerce and Challenges of Mobile Commerce}

The higher competition between business companies and popularity of mobile is increased rapidly in the last decade. Because of the advantages of the mobile, such as eliminating the distances, removing the communication barriers and providing 7/24 service to everyone, it became very important for the software and system developer companies. Customer centred organizations give primary importance to its customers. In order to adopt this new technology to customers, companies try to develop new sources and new solutions such as developing ease of use programs, user-friendly interfaces and higher security opportunities for particular transactions. Today, the mobile Internet is emerging even faster, in part because service providers, content partners, customers and investors of these markets are leveraging lessons both nationally and globally, have made significant advances enable next generation data or wireless Web services and mobile " $\mathrm{m}$ "-Commerce. Researchers have broadly defined the Mobile Commerce (m-Commerce) as it involves an emerging set of applications and services people can access from their Web-enabled mobile devices [1]. As it is stated before, this technology providing $7 / 24$ services to everyone different than the other technologies. This type of technologies can bring many advantages to country's economies and welfare. As a developing technology, additionally, m-Commerce is facing many difficulties and obstacles as an emerging market, particularly in Small Island Developing States (SIDS). The main characteristics of SIDS are stated by researchers in the literature which these states are coastal countries that share similar sustainable development challenges, including small but growing populations, with the limited resources and very sensitive to natural affects and changes [2]-[5]. They are also vulnerable to external shocks like crises. Cyprus is one of these countries. For example, lack of standards, uncompleted infrastructure, cost and speed issues are main obstacles in Cyprus for m-Commerce. Because of these external factors which affect applicability and usability issues of m-Commerce, consumer behaviour and perceptions against m-Commerce becomes negative. In some of the developed countries, like US which also face some difficulty issues such as lack of standards, high mobile telecommunication costs and low speed, survey in the literature suggested that US consumers are not convinced they want or need mobile services and many think it is simply too complicated [6]. This is in contrast to other global markets in Asia and Europe where "to going online" means reaching for a mobile handset, not turning on a PC. In Korea, for example, reports which prepared by researchers suggest that one-third of all mobile phone subscribers use their handsets for m-Commerce activities [7]. This can easily explain us the popularity of m-Commerce services and mobile usage acceptance. As it is mentioned above, the mobile service provider companies working on development of usability and applicability 
issues of m-Commerce services. But the new developments of mobile service providers may not have significant affect or changes on the customer perceptions alone. There are external and internal factors exist which may influence consumer behaviour and perceptions against m-Commerce services. The internal variables can be demographic or psychographic and external variables can be classified as social, cultural and technological. All these factors are important for to adopt consumers to use m-Commerce services. Usage of m-Commerce services have great amount of benefits for the local companies and businesses. The opportunity of 7/24 services availability gives advantages to customers to conduct transactions at anywhere-anytime and processing power which also gives an opportunity for business to offer services nationally, as well as globally. Several large companies abandon or scaling back country-based wireless efforts to focus on global markets. Additionally, carriers and content partners are still investing and bright spots exist. Several companies started to provide different services which are compatible and accessible for mobile devices. EBay recently launched a new service that lets customers bid more easily from mobile device. According to a Yankee Group report, the new service has the correct success factors-priced right, speed, and ease of use. Providing the compatible and accessible, faster and reliable services for consumer mobile devices brought a different dimension for business markets. Like eCommerce, m-Commerce also represents a huge opportunity for businesses to connect to consumers through these mobile devices at any particular time. While a set of issues warrant attention, we focus on an area that has been largely neglected applicability, usability and security issues.

Many activities compete for a user's attention on the Web. There are different mobile services sending different information such as news, stories, weather information, exchange rate information, and alerts about stock prices, and notifications of e-mail services. The environment outside of the Web is fairly stable from day to day with wired e-commerce. Most of the places like offices, workshops and homes function with a good amount of predictability, even If they experience a huge amount of activity, and relatively consistent amounts of attention can be devoted to performing tasks on the computer. In m-Commerce world, conversely, there can be a significant number of additional people, objects, and activities vying for a user's attention aside from the application itself. The particular amount of attention a consumer can give to a mobile application will vary over time, and a user's priorities can also change unpredictably. For that reason, the circumstances under which m-Commerce applications and services are used can be significantly different from those for their desktop e-Commerce counterparts.

Moreover, in the m-Commerce environment, consumers and applications must deal with different and separate devices such as phones; handhelds, telematics, and this continue to shrink in size and weight. While this brings an opportunity and achieving high device portability, usability of the devices may suffer. Traditional mice and keyboards are being replaced with buttons and small keypads. But smaller screens are difficult to read and smaller devices are difficult to use with only one hand. The usage of mobile devices affecting from the external factors like noise level, weather and brightness. Difficulties of using mobile phones such as the lack of ease of use opportunities and user-friendly interface translate into waste of time or user frustration by the consumer.

Researchers have also stated that security is another serious challenging issue in the m-Commerce environments [8]. There are potential benefits in storing sensitive data, including medical, personal, and financial information on mobile devices for use by m-Commerce applications. But the vulnerability and mobility of these devices increases the risk of losing the device and its data. Moreover, the risk of data access by unauthorized parties makes positive user identification a priority. Different safety issues also arise when user activities starts to vary. In order to prevent unauthorized access and different precautions started to implement on this environment and sometimes, these precautions makes m-Commerce services inapplicable for the particular environment or area. For example, when designing the m-Commerce systems for automobiles, serious consequences can result if the application distracts driver from the traffic and diverts too much attention from the primary task of driving. So Web access or usage of m-Commerce applications in automobiles creates potential problems associated with browsing while driving. But in addition to this, such kind of problems may be solved by designing minimal-attention interfaces. As it is mentioned above, the dynamic environment may cause problems because of it's instability and context awareness systems may warn consumers for the particular events. New designs and flexible Input/Output systems may be developed to provide ease of use which will prevent mobile device limitations and usability. Lack of data sharing and data security may cause loss of customer trust against m-Commerce services system. In order to create customer trust against these services, security must be strengthening thorough new biometrics security systems, commonsense design and legislation of the entire system. Researchers have stated the potential challenges of m-Commerce in his previous studies. Table 1 indicates some of these potential 
m-Commerce challenges and potential solutions of these problems [9].

As it is shown in Table 1, there are varieties of challenges available for M-Commerce and potential solutions in contrast to these challenges. The one of the main challenge is that while there is a significant demand available in the market, there is a minimal attention for developing m-commerce application interfaces. The dynamic environment that leads both security and safety issues as vulnerable objects, different solutions proposed such as usage of biometrics and common-sense design with legislations.

While Mobile commerce (M-Commerce) is discussed and stated, it was compulsory to discuss the e-commerce first of all. For that reason, the previous section described the commerce briefly in order to clearly define the e-Commerce which is also known as "Electronic Commerce". In order to understand the importance and role of E-Commerce, we must differentiate the e-commerce and m-commerce from each other. Researcher has explained the e-commerce as a monetary transaction which conducted using the combination of internet and a desktop or laptop computer [10]. So it's clearly stated here, the need internet connection and computer is compulsory for usability of e-commerce. As long as e-commerce has relationship between m-commerce, the same or similar tools will be required as well. For the applicability of these systems, it's again the internet connection will be compulsory.

Mobile commerce has many similarities with e-commerce. It's kind of more developed and technological based partner of commerce family. Once the wireless or any other internet connection device take place in the system, and allows clients or users and provide freedom of movement, the name of the commerce becomes "Mobile Commerce". The basic milestone of the development of M-commerce started with Wi-Fi which is called Wireless Fidelity. For that reason, the researchers defined the mobile commerce as any transactions using a wireless device that result in the transfer of monetary value in exchange for information, goods or services [11]. This definition is very similar to the e-commerce definition which is done by the researcher [10]. The role of computer or laptop is completely taken by mobile devices such as PDA's, or mobile phones. The source of communication which is provided for the data transmission is also same which is "Internet" but the devices is not switch or hub, and it's a new technology which is wireless telecommunication network devices, wireless hubs, or wireless antennas that allows users to connect to internet at anywhere and anytime. The e-commerce websites are designed for e-commerce and could be accessed through combination of computer and internet. The clients were accessing to these websites through internet and computer, conducting a transactions. In the case of m-commerce, all these websites are designed and coded according to the some compatibility standards, so clients were accessing these websites through mobiles and doing all of the same processes likewise e-commerce. Once a client accessed to the website, and transaction conducted from the mobile and through a wireless connection media, this is called Mobile commerce process. Researchers have proposed a book and defined the mobile commerce as "a monetary transaction for goods and services conducted by a mobile device, an operating system specific to mobile devices and a mobile-dedicated infrastructure." [12].

Clients are using mobile commerce applications which are developed by software developers and connecting to the internet through their GSM operators. The clients browse and surf on the company websites, by using the software that is developed for mobiles.

Since the beginning of the section, we have tried to explain the e-commerce and m-commerce. It is mentioned on the above that, m-commerce is an extension or more developed and technological way of e-commerce. But on the other hand, it must be stated that, there are very basic differences between m-commerce and e-commerce which are use of communications protocols for transactions, types of internet connection and the connection media, the key enabling technologies, and development languages.

Table 1. M-Commerce challenges and potential solutions [9].

\begin{tabular}{cc}
\hline Challenges & Potential Solutions \\
\hline Increased demands on attention & Minimal-attention interfaces \\
Dynamic environment & Context awareness \\
Mobile device limitations and usability & New and flexible I/O modalities \\
Security & Biometrics \\
Safety & Commonsense design and legislation \\
Social concerns & Societal norms and written laws
\end{tabular}


For example, while the m-commerce is giving freedom of movement to the clients, it requires Wireless Application Protocol (WAP) which is a key for enabling the m-commerce technology. Clients access to the internet through the WAP technology and access/browse the pages. All data and packet transmission from the wireless media provided through WAP. So the WAP becomes a communication standard for the m-commerce. But in e-commerce technology, we do not need the WAP technology to enable us to connect to internet. Instead of this, the computer use Hyper Text Transfer Protocol (HTTP) and standardize the pages using Hyper Text Markup Language (HTML) in order to browse/show pages by using internet browser. On the other hand, WAP requires Wireless Markup Language in order to standardize the formatting of pages and display them on the mobile devices.

\section{Customer Loyalty and Trust in Mobile Commerce}

The concept of trust has been studied in different disciplines ranging from business to psychology to medicine, and perspectives on it differ, but it can be loosely defined as "a state involving confident positive expectations about another's motives with respect to oneself in situations entailing risk” [13]. Business relationship would be nonexistent without trust, which is expressed in various business contexts such as laws, contracts and regulations as well as in company policy and personal reputations, and long term relationships. Once the customer trust is gained by the business, this situation becomes long-term relationship between the customer and business and it transforms to loyalty during the particular period of time. Not surprisingly, studies show trust also plays an essential role in successful Internet retailing [14]. Gaining customer trust in m-Commerce is a frustrating process, extending from initial trust formation to continuous trust development-but it can be done. Studies by researchers shows nearly all customers refuse to provide personal information to a Web site at one time or another, a majority because they lack trust in the site [15]. Most of these customers are still not comfortable with the concept of Web-based developments and the electronic medium itself. They are distrustful that e-Commerce can satisfy consumer needs unfulfilled in the bricks-and mortar business world, and they wonder whether e-Commerce is technologically feasible, and reliable. From this uncertainty point of view, it's a small step for customers to doubt the integrity of Internet vendors. Without social cues, and personal interaction such as body language, linguistics, the observation of other buyers, and the ability to feel, touch, and inspect products directly, customers can perceive online business and transactions as riskier in nature.

According to researchers [16], gaining consumer trust in m-Commerce world, which uses radio-based wireless devices to conduct business transactions over the Web-based e-commerce system, is particularly frustrating task because of its unique features. As it is stated about m-Commerce challenges on the previous paragraphs, mobile devices are terrifically convenient for anytime shopping, and offering various types of advantages both the consumers and businesses. But their small screens, low resolution displays and tiny multifunction keypads make developing user-friendly interfaces and graphical applications a challenge. Comparatively, mobile handsets are also limited in computational power, memory and batter life. Once it is considered that, m-Commerce is involved into the Wireless Networks; major limitations of these networks must be taken into consideration. These networks have difficulties of providing huge bandwidths and they have connection stabilities as well as function predictabilities. Also, relatively high operation costs, lack of standardized protocols and data transmitted wirelessly is more vulnerable to eavesdropping.

Various factors may influence the complex process of engendering customer trust in Internet shopping. These are the factors and variables that influence consumer behaviour such as internal-demographic, psychographic and external-social, cultural and technological variables. The consumer characteristics such as need, motivation, capacity and willingness, along with the seller characteristics such as ability, benevolence, and integrity, all play a role in Internet purchasing and m-Commerce usage behaviour [17]. Customer perception of security and privacy control, integrity, and competence, as well as third-party recognition and legal framework are important antecedents of trust in Internet shopping [18]. There are several other factors exist which may influence customer trust and trigger Internet shopping such as personal experience, familiarity, affiliation and belonging, transparency, factual signals and heuristic cues. Table 2 indicates some of the factors which may influence consumer behaviour against m-Commerce and Internet shopping.

\section{Research Model Formulation}

There is a need for determination of variables in the hypothesis creation progress. The determinants that impact 
Table 2. Factors influence consumer behaviour against internet shopping.

\begin{tabular}{ccccc}
\hline Category & $\begin{array}{c}\text { Consumer } \\
\text { Characteristics }\end{array}$ & $\begin{array}{c}\text { Seller } \\
\text { Characteristics }\end{array}$ & $\begin{array}{c}\text { Consumer } \\
\text { Perceptions }\end{array}$ & $\begin{array}{c}\text { Consumer Perceptions for } \\
\text { Corporate Branding }\end{array}$ \\
\hline Need & Ability & Security & Personal Experience \\
Motivation & Benevolence & Privacy Control & Familiarity \\
Factors & Capacity & Integrity & Integrity & Affiliation and Belonging \\
& Willingness & & Competence & Transparency \\
& & Third-party recognition & Factual Signals and Heuristic cues \\
\hline
\end{tabular}

the hypothesis testing as internal or external should be classified and explained. This section explains the formulation of research model in details.

Figure 1 shows the general research model formulation. The impact of determinants which affects the mobile commerce customers is divided into two (2) categories of variables which are Internal and External variables. As it is shown below, internal variables are classified as demographic and psychographic, external variables classified as social, cultural and technological variables. In this study, two (2) hypotheses are formulated through the impact of internal and external variables towards the mobile commerce. The variables which mentioned above would be discussed clearly later sections of this study.

\subsection{Formulation of Research Objectives and Hypothesis}

To identify the impact of internal variables (demographic and psychographic variables) on consumer behaviour towards mobile commerce;

H1: There is a significant impact of internal variables (demographic and psychographic variables) on consumer behaviour towards mobile commerce

To identify the impact of external variables (social, cultural and technology variables) on consumer behaviour towards mobile commerce;

H2: There is a significant impact of external variables (social, cultural and technology variables) on consumer behaviour towards mobile commerce.

There are 4 different types of variables exist which are classified as, dependent, independent, moderating and intervening variables. In this research, some of these variables are shown and classified in Figure 2.

Figure 2 is showing the classification of the variables during the formulation of the hypothesis.

The variables which are classified under the Psychographic variables referring to any other attribute related to personality, lifestyle, values, interests or attributes. These factors consider various influences on a person's buying behaviour. Different lifestyle choices like parenting, exercise decisions, religion, marriage or health can greatly affect a person's requirements or preferences for certain products or services.

Technological Variables; was developed to measure and categorise consumers based on ownership, use patterns and attitude towards different technologies. A concrete example would be humanity's attitude towards the Internet. There are distinct differences between frequent Internet users and those who seldom use it. Most experienced Internet users are more affluent and tend to be more optimistic towards modern technology than those who are not as manifested by the number of online shoppers. Confident online shoppers are those who have been using the Web for quite sometime thus, making them feel safer compared to newly recruited Web users.

The behavioural variable of market segmentation groups consumers in terms of occasions, usage, loyalty and benefits sought. This is based on the way different consumers respond to, use or know a product or service. The variable of occasion simply means the occasion on which a product or service is consumed or purchased.

\subsection{Range of Study and the Sample Selection}

This study focuses the students of Research center in Cyprus. Students from different research departments are participated in this project. The total number of students who participated in this project is 100 . The total population of the research center is approximately 971. 


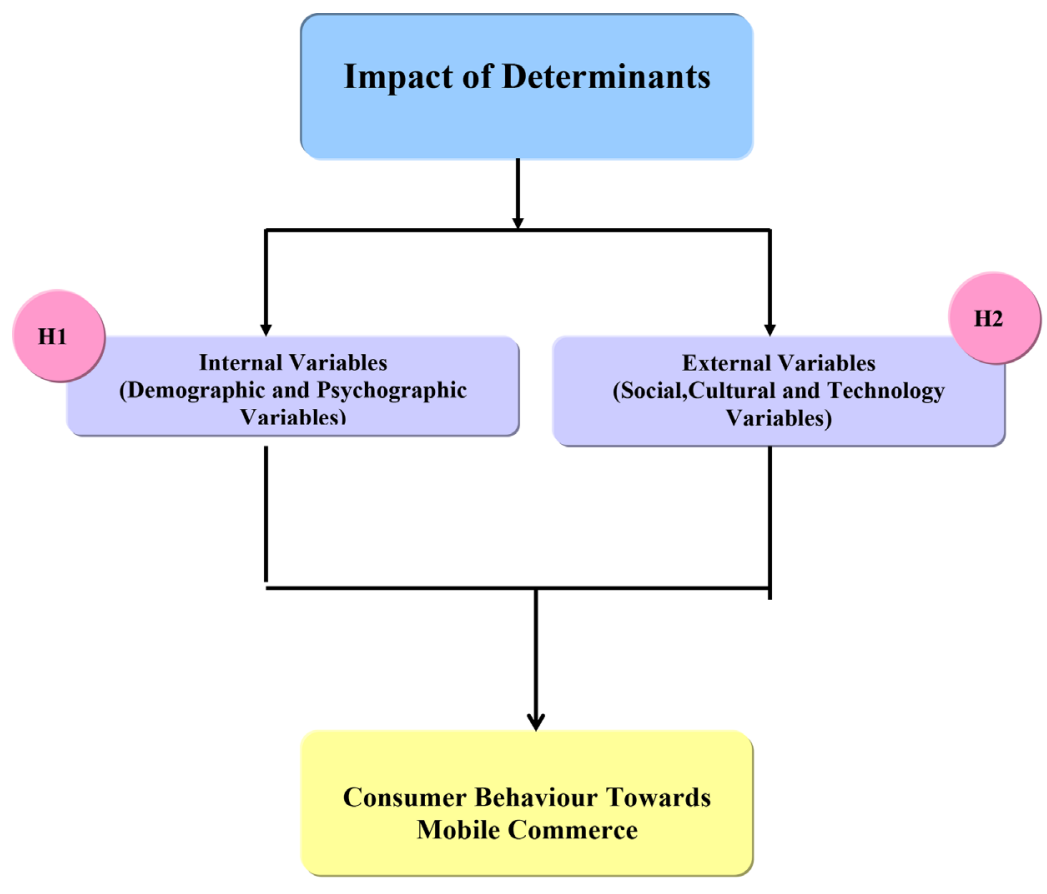

Figure 1. Research model formulation.

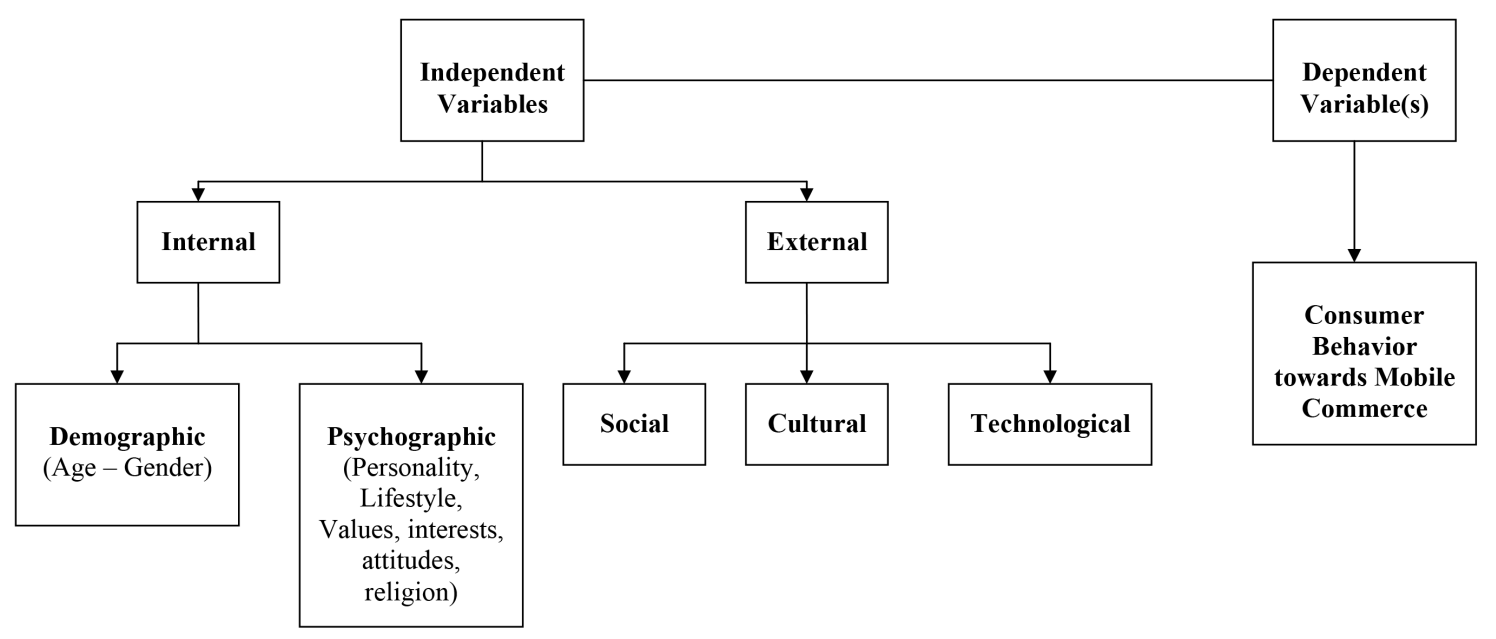

Figure 2. Dependent and independent variables classifications.

\subsection{Data Collection}

In this research, two different sources are used to accomplish the objectives of this study. The primary sources and the secondary sources.

\subsubsection{The Primary Sources}

The primary source for this research is the information collected through questionnaires. The information obtained from this source has provided statistics, which measure the students' behaviour against mobile commerce applications.

\subsubsection{Secondary Sources}

The secondary sources will be gathered from references and published books, journals and information available on the internet. Additionally, some data obtained from the particular websites from the Internet. 


\subsection{Sample Plan}

The following sample units have been selected based on the following methods and the sample units ought to have requisite criteria to get selected for the study.

- Should be a student of Cyprus Research center.

- Should be registered to one of the programs at Cyprus Research center.

- The participants should be aware of the mobile commerce applications.

- The participants should be able to use mobile commerce applications.

- The participants should have a mobile device that is compatible to mobile commerce applications.

\subsection{Sampling Technique}

A simple random sampling has been used to select target respondents for this study. The students of Research Centre have been informed on the purpose of the study and the willing students participated in the study. Responders for the survey were randomly selected 100 individual people from Research Centre. The sample population include only students as well as those students who work outside as well.

\subsection{Sample Size}

The sampling size is used for this research study is One Hundred $(\mathrm{N}=100)$.

\subsection{Research Tools and Collection Instrument}

The instrument used for collecting the primary data is questionnaire. The questionnaire is a structured questionnaire. Selective questions were asked and respondents just ticked appropriately. Open ended questionnaire was used for the pilot study and the result of the open ended questionnaire was used to formulate the closed end structured questionnaire.

\subsubsection{The Questionnaires}

The collection method used is hand delivery of the structured questionnaire to the respondents personally by the researcher of this study. This was done in order to ensure the respondents understand the questions before ticking appropriately. The structured questionnaire was also translated into Turkish language for easy understanding by the respondents.

Questionnaires are one of the most widely used social research techniques. The questionnaires will be utilized to gather information from subjects. This is to explore the impact of determinants on consumer behaviour against mobile commerce applications and mobile commerce as well. Researchers stated that "Questionnaire is one of the most widely used survey data collection techniques, because each respondent is asked to response to the same set of questions, it provides an efficient way of collecting responses from a large sample prior to quantitative analysis” [19].

There are two main types of surveys, questionnaire and interviews. The method selected for this research was the questionnaire. The questionnaire are classified into two types; those which are designed for self-completion in which the respondent complete the questionnaire themselves, and those which designed for assisted completion wherein the researcher asks the questions and fill in the questionnaire himself [20].

\subsubsection{The Design of the Questionnaire}

The contents of the questionnaires were mainly derived from the literature review. In addition, from some research and studies conducted in this field.

The questionnaire is developed in English but because of the student's profile at Research Centre of Cyprus and as it is stated before; the questionnaire is also translated into Turkish. This action has granted two main factors for the questionnaire;

Firstly, helped in saving time spent with respondent to translate and explain the questionnaire elements. Secondly, it guaranteed the highest level of understanding of the questionnaire items and the ideal amount of freedom for answering.

\subsubsection{The Questionnaire Contents}

The questionnaire containing totally 10 questions. The first 3 questions were designed to gather main general 
information of the respondents such as age, sex, nationality, occupation and monthly income. The question number four to question number eight containing the questions about the frequency of conducting mobile commerce transactions and measuring the frequency of usage of mobile commerce. Especially, question number six, is measuring the usage of particular mobile commerce transactions.

The last 2 questions were designed to examine the consumer's satisfactions and perceptions against mobile commerce applications and their recommendations about mobile commerce. The question number 9 is 5 point scale designed question and measuring the replies in five ranks. This question was measuring the actual reason of usage of M-Commerce by people. It also shows the personality, perceptions and the consumer behaviour against mobile commerce applications. The more details about this question are given in the "Findings" section of this study.

The questionnaire in the study was designed for the Bachelor students who are studying in any faculty and department of Cyprus Reserach Center. Single questionnaire was given to each respondent which containing the questions about his or her perceptions, and particular behaviour which determining the influencing factors of Mobile commerce usage. The questionnaire contained questions used to determine the demographic distribution as well as perceptions and behaviours of the respondents. Question 1 was based on the age distribution of the respondents; Below 20, 21 - 30, 31 - 40, 41 - 50, and above 50 years. Question 2 was based on the gender of the respondents; Male or Female. Question 3 was based on the nationality of the respondent, Turkish Cypriot, Turkish, British and Others. Question 4 was designed based on the occupation of the respondents, which could be; Student, Private, Business, Housewife. Question 5 was designed based on the Monthly Income of the respondents in terms of Turkish Liras (TL) and which can be; Below 1000, 1001 - 2000, 2001 - 3000,3001 - 4000 and above 4000. Question 6 was based on the mobile different types of commerce transactions and it was aiming to find out the most frequently done mobile commerce transactions by the consumers. Question 7 was designed to find out conducting the mobile commerce frequency of consumers which is limited with last 12 months time period and can be; Once, 2 - 4 times, 5 - 10 times, More than 10 times. Question 8 is designed for to measure the amount of money spent on m-commerce transactions in terms of Turkish Lira and which can be; Below 50, 51 - 100, 101 - 150, 151 - 200 and Above 200. The Question 9 is designed based on the "Five Points Likert” scale. The respondents were asked to rank their interests (against using mobile commerce services) using highly agrees as the highest and highly disagrees as the least. Question 10 was designed for to measure the recommendation of mobile commerce by respondents to their relatives and friends which can be; Definitely Recommend, Somewhat recommend, No Comments, Do Not Recommend, Not at All.

\subsubsection{The Questionnaire Responses}

The questionnaire was targeting to all students at all faculties in Research Center. It was necessary to distribute the questionnaires to most of the departments of these faculties. The 100 questionnaires were been distributed, 100 of them collected, and none of the questionnaires rejected because of incompletion or as an unfilled.

\subsection{Limitation of the Study}

There are specific limitations exist for this research. These are:

- The data collected were purely based on knowledge, perception, feelings, attitude and opinions of the target respondents.

- The research would have the limitation like all the social science research does.

- The study had been conducted in Cyprus Research Centre and the results could not be generalized.

\section{Findings}

In this section the analysis of the survey will be highlighted and discussed. The mobile commerce service providers and applications developers keep conducting the researches to understand the customer profiles and analyze their needs in order to create better and secure mobile applications. But people perceptions differ and behaviour may vary depending on the time, place and corresponding action. The survey of this research shows the different perceptions of people, their actual reasons of usage of the mobile commerce applications, their problems with this technology and their recommendations. Additionally, each questionnaire is analyzed carefully, and consumer's viewpoints measured in this research. Moreover, people spending on mobile commerce, and their main reasons of usage of this technology became some of the major interesting outcomes of this study. 


\subsection{General Information about the Sample}

This analysis is based on the data collected from 93 respondents. As it is mentioned before, responses from 100 respondents could succeed \%100 and no unfilled-uncompleted questionnaires received. 100 respondents from different faculties and different departments of Cyprus Reserach Center. The demographic information includes nationality, age, sex, occupation and monthly income.

\subsection{Age Group}

With regard to the age, out of the total number of students in the sample, between 21 - 30 years old represent the largest proportion which is 92\% (92 respondents) and 8\% of respondents participated in this research project. There is no respondent participated in this project above 30 years old. Figure 3 and Table 3 shows the same information about the distribution of population in different ways.

Inference: From the Figure 3, Table 3 and analysis, it can be inferred that majority of the respondents used for this study are below 30 years old. Only 8\% of respondents are in the category of "Below 20" years old.

\subsection{Gender Ratio}

Table 4 shows that, there are totally 68 male respondents and 32 female respondents participated in this survey. Figure 4 shows number of respondents participated in this survey in a chart model.

Inference: From the above analysis, it can be inferred that majority of the respondents used for this study are male.

Table 3. Age frequency of respondents.

\begin{tabular}{ccc}
\hline Age & Number of Respondents & \% of Respondents \\
\hline Below 20 & 8 & $8 \%$ \\
$21-30$ & 92 & $92 \%$ \\
$31-40$ & 0 & $0 \%$ \\
$41-50$ & 0 & $0 \%$ \\
Above 50 & 0 & $0 \%$ \\
Null & 0 & $0 \%$ \\
Total & 100 & $100 \%$ \\
\hline
\end{tabular}

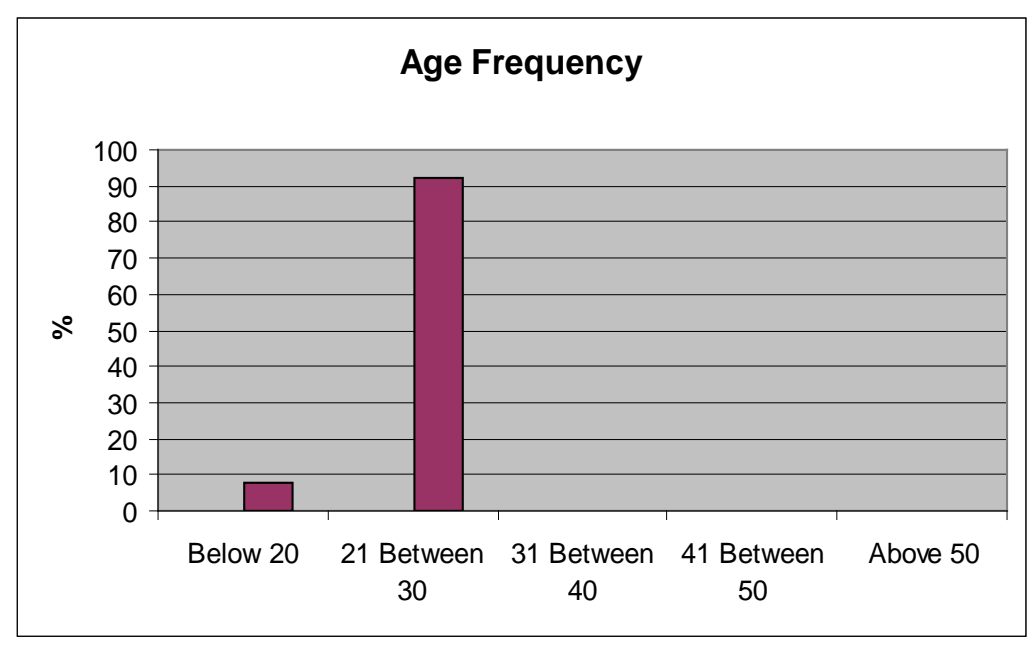

Figure 3. Age frequency of respondents. 


\subsection{Nationality Distribution of Respondents}

The nationality distribution of the sample is given in Table 5 and Figure 5. According to Table 5, there are totally 13 Turkish Cypriot respondents (13\%), 50 Turkish respondents (\%50), 0 British respondents (0) and 28 other's nationality holder's respondents (28\%) participated in this survey.

Inference: According to the data gathered and analyzed above, it shows that majority of participants are Turkish and Other nationality citizens. The Turkish Cypriot citizens have the minority of contribution in this survey. There is no British citizen participant exist in this survey.

Table 4. Gender ratio of respondents.

\begin{tabular}{ccc}
\hline Gender & Number of Respondents & \% of Respondents \\
\hline Male & 68 & $68 \%$ \\
Female & 32 & $32 \%$ \\
Null & 0 & $0 \%$ \\
Total & 100 & $100 \%$ \\
\hline
\end{tabular}

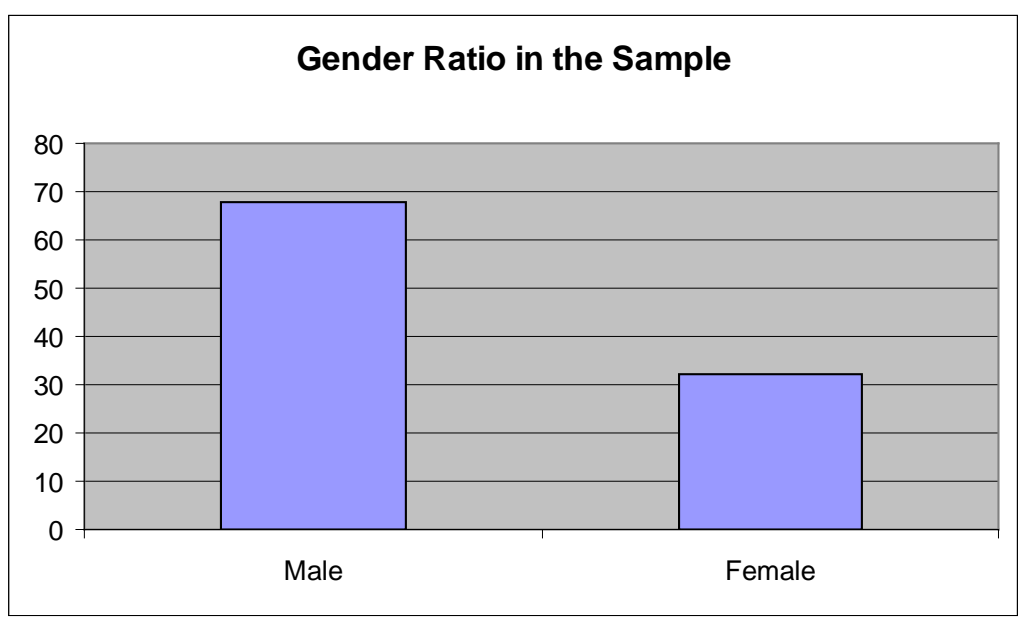

Figure 4. Gender ratios of respondents.

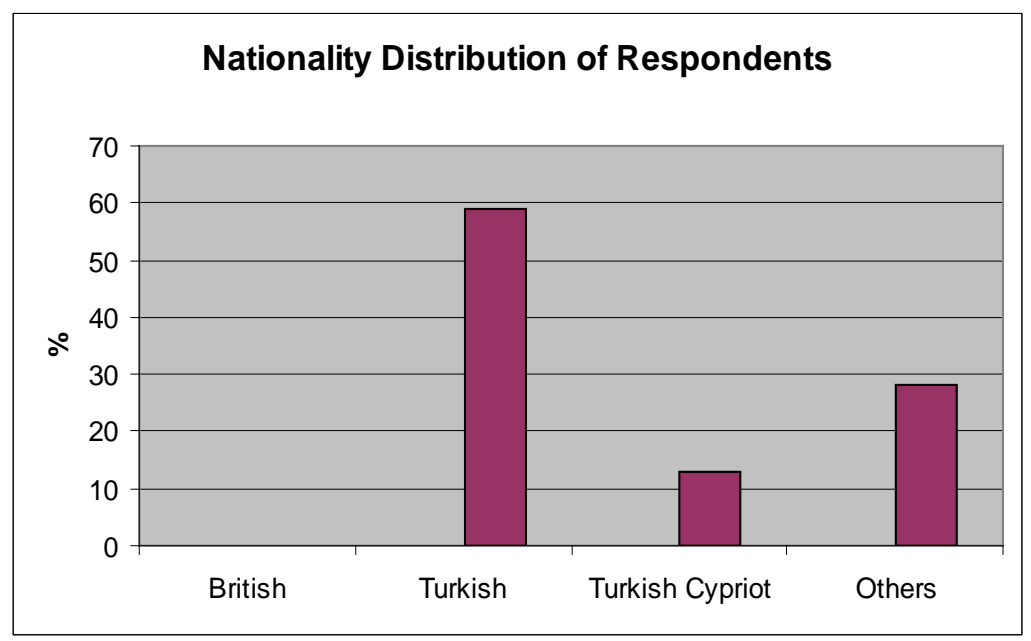

Figure 5. Nationality distributions of respondents. 


\subsection{Occupation of Respondents}

In this analysis, it is found that the highest percentage of respondents is students. Table 6 is showing the occupation of the respondents. According to Table 6, there are 100 (\%100) of students participated in this research and there is $0(0 \%)$ of workers or housewife attended or involved in this survey.

Inference: Figure 6 and Table 6 show the distribution of occupation among participants. According to these results, it can be said that, all participants who participated in this survey was students.

\subsection{Income Ratios of Respondents}

The data shown below on the. Table 7 is showing the Monthly income of the respondents who participated in the survey. According to Table 7, there are 100 (\%100) of respondents participated in this research who had a salary of below $1000 \mathrm{TL}$ and there is $0(0 \%)$ of respondents participated who has salary more than $1000 \mathrm{TL}$ in this survey.

Table 5. Nationality distribution of respondents.

\begin{tabular}{ccc}
\hline Nationality & Number of Respondents & \% of Respondents \\
\hline Turkish Cypriot & 13 & $13 \%$ \\
Turkish & 59 & $59 \%$ \\
British & 0 & $0 \%$ \\
Others & 28 & $28 \%$ \\
Total & 100 & $100 \%$ \\
\hline
\end{tabular}

Table 6. Rate of occupation in the survey.

\begin{tabular}{ccc}
\hline Nationality & Number of Respondents & \% of Respondents \\
\hline Student & 100 & $100 \%$ \\
Private & 0 & $0 \%$ \\
Business & 0 & $0 \%$ \\
Housewife & 0 & $0 \%$ \\
Total & 100 & $100 \%$ \\
\hline
\end{tabular}

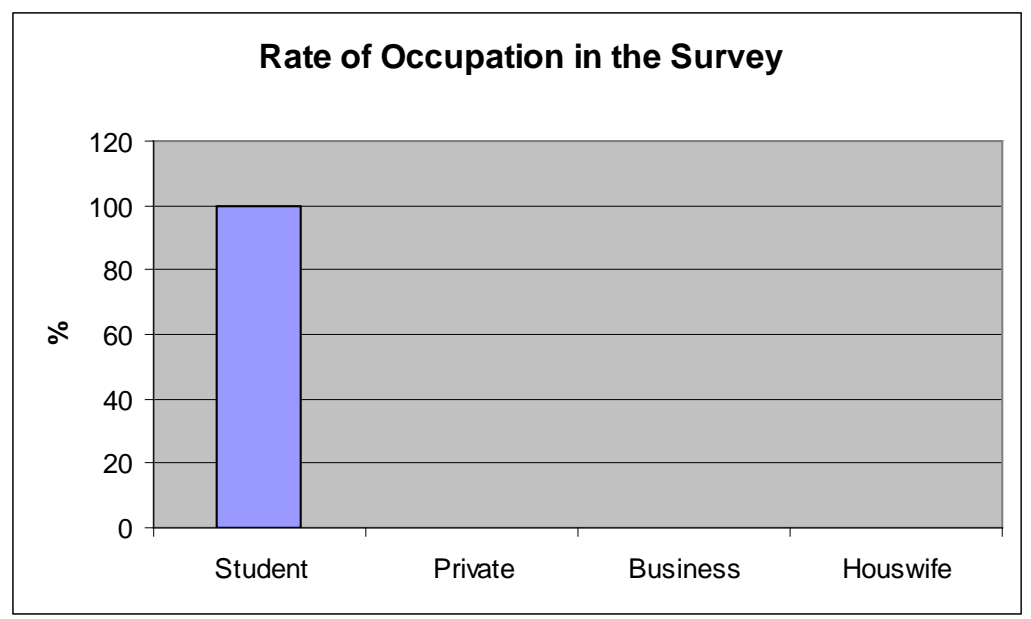

Figure 6. Rate of occupation in the survey. 
Table 7. Income ratios of respondents.

\begin{tabular}{ccc}
\hline Income (TL) & Number of Respondents & \% of Respondents \\
\hline Below 1000 & 100 & $100 \%$ \\
$1001-2000$ & 0 & $0 \%$ \\
$2001-3000$ & 0 & $0 \%$ \\
$3001-4000$ & 0 & $0 \%$ \\
Above 4000 & 0 & $0 \%$ \\
Total & 100 & $100 \%$ \\
\hline
\end{tabular}

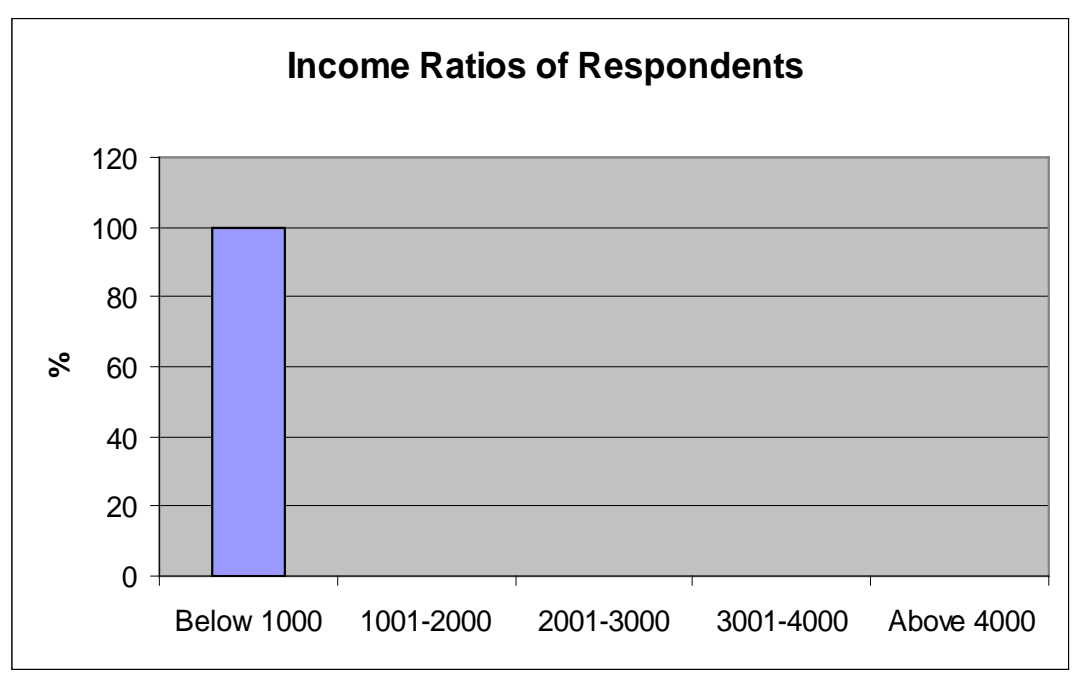

Figure 7. Income Ratios of respondents.

Inference: Figure 7 and Table 7 show the distribution of income ratios among participants. According to these results, it can be said that, all participants who participated in this survey has a monthly income of less then or equal to $1000 \mathrm{TL}$.

\subsection{Types of Mobile Commerce Transactions by Respondents}

Table 8 is showing the types of M-Commerce transactions conducted by the respondents. It is important to state that, majority of respondents who participated in this research prefer interactive services such as chats and games (79\%). Most of the respondent mentioned about the "facebook" and "twitter" web addresses at the time of distribution of the questionnaire. Only a few respondent selected ringtones which is equivalent to $10 \%$ (10 respondents), $2 \%$ of respondents (2 respondents) and 5\% (5 respondents) selected Music and Content which showing that they involved into m-commerce applications and services for this case.

None of the respondents involved into the services of mobile commerce such as, admissions to events, parking, or others. The respondents also mentioned that, they could not involve into these services just because of the unavailability of these services, or they could not find it beneficial for themselves. Figure 8 is showing this distribution clearly.

Inference: The stated analysis and table-figure above shows that, respondents who participated in this survey, prefer social activities, such as chatting or web-forums. This also can be considered as one of the difference because of the respondent's age group and business. On the other hand, other selections which are not selected by the respondents should also be considered carefully. 


\subsection{Frequency of Mobile Commerce Transactions by Respondents}

Table 9 below is showing the frequency of m-commerce transactions done by respondents for the last 12 months. The majority of respondents (45\%) replied as they have conducted a transaction more than 10 times for last 12 months. 33\% of respondents replied as 5 - 10 times, $18 \%$ of respondents replied as $2-4$ times and $4 \%$ of respondents replied as they have conducted a transaction just once.

Inference: According to the analysis, it can be said that, majority of respondents have conducted mobile commerce transaction for last 12 months. However, there are other respondents exist, who did not conduct this much of transaction for different reasons which they have not stated. Figure 9 is showing the frequency in a bar chart model.

Table 8. Types of m-commerce transactions done by respondents.

\begin{tabular}{ccc}
\hline Type of Services & Number of Respondents & \% of Response \\
\hline Ringtones & 10 & $10 \%$ \\
Screen Savers & 4 & $4 \%$ \\
Music and Video Content & 5 & $5 \%$ \\
$\begin{array}{c}\text { Interactive services, such } \\
\text { as chats, games etc. }\end{array}$ & 79 & $79 \%$ \\
$\begin{array}{c}\text { Information services, such } \\
\text { as weather forecasts, } \\
\text { traffic information etc. }\end{array}$ & 2 & $2 \%$ \\
Admissions to events & 0 & $0 \%$ \\
Parking & 0 & $0 \%$ \\
Other & 100 & $100 \%$ \\
\hline
\end{tabular}

Table 9. Frequency of m-commerce transactions done by respondents for last 12 months.

\begin{tabular}{ccc}
\hline Frequency & Number of Respondents & \% of Respondents \\
\hline Once & 4 & $4 \%$ \\
$2-4$ Times & 18 & $18 \%$ \\
$5-10$ Times & 33 & $33 \%$ \\
More Than 10 Times & 45 & $45 \%$ \\
Total & 100 & $100 \%$ \\
\hline
\end{tabular}

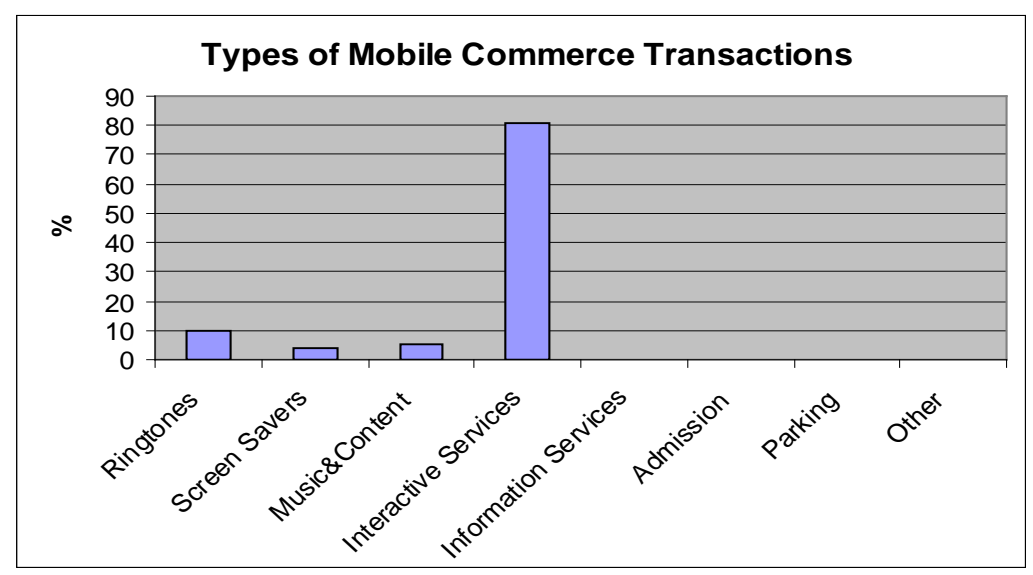

Figure 8. Types of m-commerce transactions done by respondents. 


\subsection{Amount of Money Spent on Mobile Commerce Applications}

Figure 10 and Table 10 showing the amount of money spent on Mobile commerce applications for last 12 months by the respondents. According to this data, 63\% (63 respondents) spend less than 50 TL, 28\% of respondents spend $51-100 \mathrm{TL}, 9 \%$ of respondents spend $101-150 \mathrm{TL}$ and $0 \%$ of respondents spend more than $101 \mathrm{TL}$ on the mobile commerce transactions.

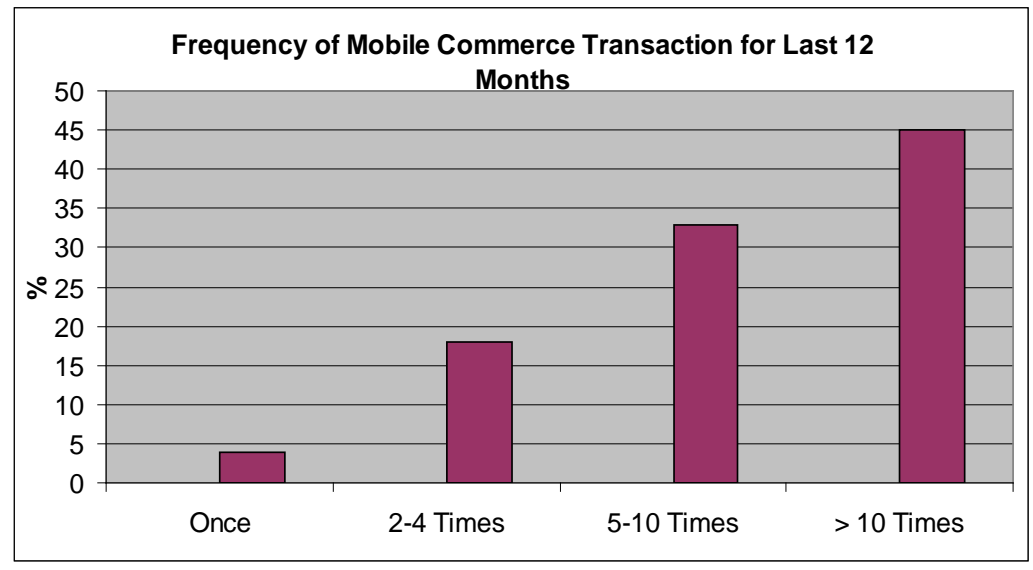

Figure 9. Types of m-commerce transactions done by Respondents for last 12 months.

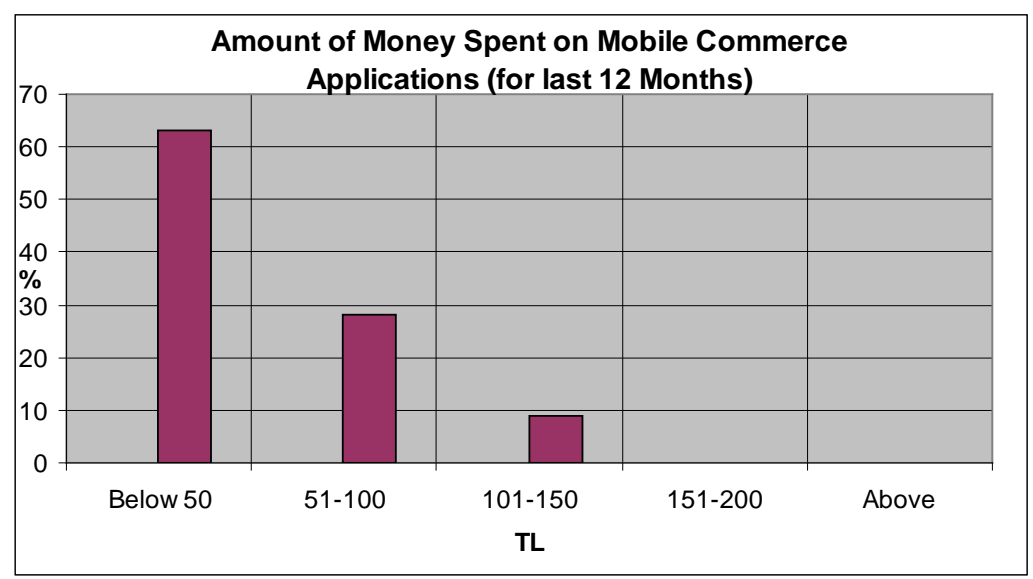

Figure 10. Amount of money spent on mobile commerce applications for last 12 months.

Table 10. Amount of money spent on mobile commerce applications for last 12 months.

\begin{tabular}{|ccc|}
\hline Amount of Money (TL) & Number of Respondents & \% of Respondents \\
\hline Below 50 & 63 & $63 \%$ \\
$51-100$ & 28 & $28 \%$ \\
$101-150$ & 9 & $9 \%$ \\
$151-200$ & 0 & $0 \%$ \\
More Than 200 & 0 & $0 \%$ \\
Total & 100 & $100 \%$ \\
\hline
\end{tabular}


Inference: According to the information gathered from the questionnaire analysis, it can be said that, a minority of respondents spend considerable amount of money on mobile commerce applications and majority of respondents spend less then 50TL on Mobile commerce applications.

\subsection{Agreement Level of Respondents}

Table 11 is showing the agreement levels of respondents against different statements. According to these statements only.

Inference: Table shows us the agreement level of some causes and it is found out that only first 4 ranks, $1^{\text {st }}$ $2^{\text {nd }} 3^{\text {rd }} 4^{\text {th }}$ rankings was highly agreed. According to this situation, it can be said that, due to occupation, marital status, because the popularity of technology and people characteristics effect the usage of mobile commerce.

\subsection{Recommendation of Mobile Commerce Transactions by Respondents}

Table 11 is showing the respondents recommendation of Mobile Commerce transactions to their relatives and friends. According to the gathered and analyzed data, \%75 of respondents (75 respondent) answered as definitely recommend, \%12 of respondents (12 respondent) answered as somewhat recommend, \%10 of respondents (10 respondent) answered as No Comment, and 3\% of respondents (3 respondent) answered as do not recommend the mobile commerce transactions for their friends and relatives.

\section{Table 11. Agreement level of respondents.}

\begin{tabular}{|c|c|c|c|c|c|}
\hline S. No & Statements & Score & S. Score & Rank & Agreement Leve \\
\hline 1. & I use mobile commerce transactions because I am single & 242 & 12.1 & 17 & Disagree \\
\hline 2. & I use mobile commerce transactions because I am married & 364 & 18.2 & 4 & Highly Agree \\
\hline 3. & I use mobile commerce transactions because I have children & 269 & 13.5 & 16 & Disagree \\
\hline 4. & I use mobile commerce transactions because I am educated & 277 & 13.9 & 13 & Disagree \\
\hline 5. & I use mobile commerce transactions due to my occupation & 370 & 18.5 & 3 & Highly Agree \\
\hline 6. & I use mobile commerce transactions because I have high income & 236 & 11.8 & 18 & Disagree \\
\hline 7. & $\begin{array}{l}\text { I use mobile commerce transactions because I like to live a good life } \\
\text { style }\end{array}$ & 226 & 11.3 & 19 & Disagree \\
\hline 8. & $\begin{array}{l}\text { I use mobile commerce transactions because I want to show myself } \\
\text { different from my friends }\end{array}$ & 325 & 16.3 & 10 & Agree \\
\hline 9. & $\begin{array}{l}\text { I use mobile commerce transactions because I want show myself } \\
\text { modern to my friends }\end{array}$ & 274 & 13.7 & 14 & Agree \\
\hline 10. & $\begin{array}{l}\text { I use mobile commerce transactions because everyone in my society } \\
\text { uses the same }\end{array}$ & 341 & 17.05 & 7 & Agree \\
\hline 11. & $\begin{array}{l}\text { I use mobile commerce transactions because I want to get } \\
\text { appreciation from society }\end{array}$ & 329 & 16.5 & 8 & Agree \\
\hline 12. & $\begin{array}{l}\text { I use mobile commerce transactions because I want the society to } \\
\text { respect me }\end{array}$ & 273 & 13.7 & 15 & Agree \\
\hline 13. & $\begin{array}{l}\text { I use mobile commerce transactions because it is suitable to my } \\
\text { culture }\end{array}$ & 284 & 14.2 & 11 & Agree \\
\hline 14. & $\begin{array}{l}\text { I use mobile commerce transactions because it is useful for my work } \\
\text { culture }\end{array}$ & 341 & 17.1 & 6 & Agree \\
\hline 15. & $\begin{array}{l}\text { I use mobile commerce transactions because it helps me to align } \\
\text { with my culture }\end{array}$ & 282 & 14.1 & 12 & Agree \\
\hline 16. & $\begin{array}{l}\text { I use mobile commerce transactions because the technology save my } \\
\text { time and money }\end{array}$ & 356 & 17.8 & 5 & Agree \\
\hline 17. & $\begin{array}{l}\text { I use mobile commerce transactions to show I am a tech savvy (lover } \\
\text { of technology) }\end{array}$ & 373 & 18.7 & 2 & Highly Agree \\
\hline 18. & $\begin{array}{l}\text { I use mobile commerce transactions because it is the latest } \\
\text { technology on commerce }\end{array}$ & 387 & 19.4 & 1 & Highly Agree \\
\hline
\end{tabular}


Table 12. Recommendation of mobile commerce transactions by respondents.

\begin{tabular}{ccc}
\hline Opinion & Number of Respondents & \% of Respondents \\
\hline Definitely Recommend & 75 & $75 \%$ \\
Somewhat Recommend & 12 & $12 \%$ \\
No comments & 10 & $10 \%$ \\
Do not Recommend & 3 & $3 \%$ \\
Not at all & 0 & $0 \%$ \\
Total & 100 & $100 \%$ \\
\hline
\end{tabular}

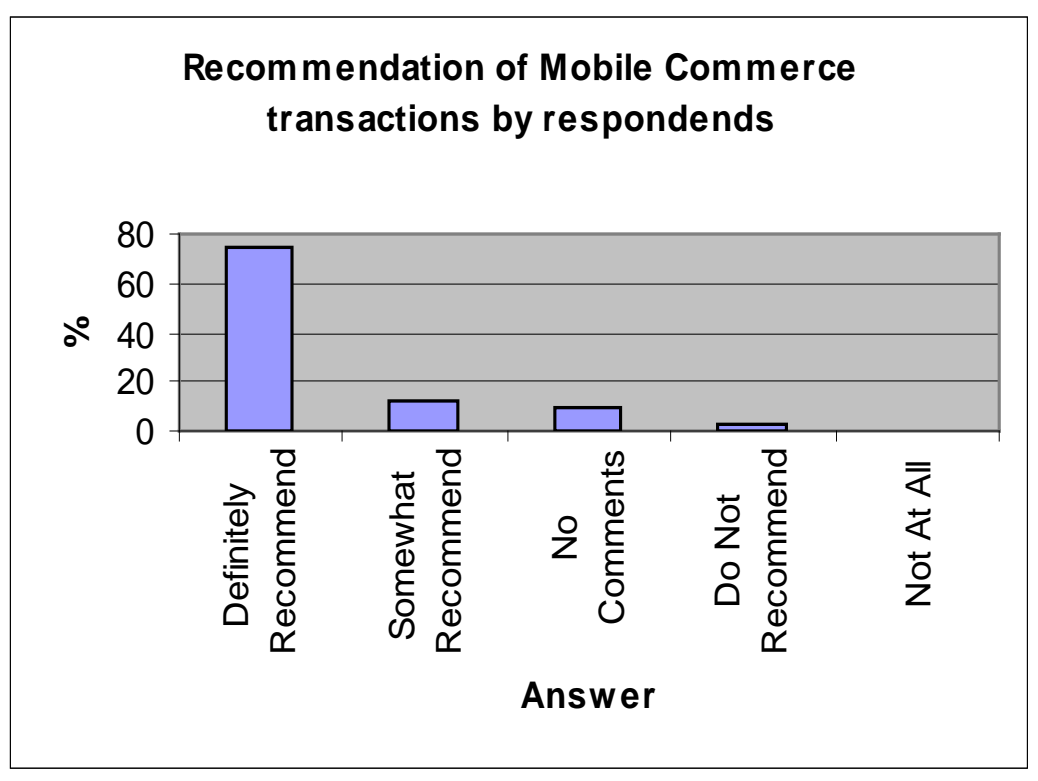

Figure 11. Recommendation of Mobile Commerce transactions by respondents.

Inference: According to the data in Table 12 and Figure 11, it can be said that majority of respondents definitely recommend mobile commerce transactions, and very small minority of respondents do not recommend this technology. However, there are respondents exist in the middle who actually somewhat recommend or have no idea about this technology. It must be important to consider that portion of the sample.

\section{Hypothesis Testing}

At the Hypothesis formulation section of this study, the following hypothesis have been formulated which are;

H1: There is a significant impact of internal variables (demographic and psychographic variables) on consumer behaviour towards mobile commerce

H2: There is a significant impact of external variables (social, cultural and technology variables) on consumer behaviour towards mobile commerce.

According to the answers we gathered from the respondents and analyzing of these data, results are showing us that, $\mathrm{H} 1$ and $\mathrm{H} 2$ are correct. Because demographic and psychographic variables affecting the respondents behaviour towards mobile commerce in this study. Table 11 showing the rankings of the ideas which gathered from the questionnaires of respondents. According to that information, usage of mobile commerce applications affected due to occupation, marital status, and because of the popularity of this technology in market and as well as people characteristics effect the usage of mobile commerce. This is showing that, both internal and external variables have a significant impact on mobile commerce. 


\section{Conclusions \& Recommendations}

This study was conducted on a small region of the country, but it can be a sample to analyse the consumer behaviour towards mobile commerce to provide better services or improve existence services in the regions. The findings can show us that, respondents are technology savvy and like technological improvements and developments. Some limitations may exist as mentioned above, and additionally, the competition between the mobile service providers can be one of the handicaps for mobile commerce services.

As it is stated at the end of the findings section, the outcome of the study can show us that people do not spend too much money on the mobile commerce transactions. However, Section 4.6 indicated that, the interactive services, such as chatting, games, etc. are most popular mobile commerce services used by the respondents.

Especially, some of the respondents stated that, the facebook and twitter web sites are the most visited and important websites for them. In this case, it is important to highlight those free access services launched by the mobile service providers in this region such as facebook, twitter and messenger and this must be considered as one of the reasons of low amount of money spent on mobile commerce transactions an outcome. On the other hand, because of the lack of mobile commerce infrastructure from the security point of view in the region, most of the m-commerce consumers couldn't highly satisfy. The study can be conducted by considering what type of services of mobile commerce is used by consumers, and under what circumstances consumer will rely on these services. Because some of the consumers, especially in such a region which infrastructure is not completely secure, the m-commerce cannot go further than a simple chatting tool and it cannot be used as a transaction tool for businesses as well as consumers.

Since this study has conducted at Cyprus Research Centre, it has limitations because of limited resources, time and population. It must be stated that, the research outcomes may vary if it conducts on different regions of the country with different populations.

Research outcomes may rely on the respondent's profile, or different characteristics of the respondents. This specific research is conducted mainly with the university student's participation. The student's perception against mobile commerce technology and monetary income may affect the outcomes of the study.

Mobile commerce applications can become more popular by providing more services, and customer feedback. People ideas and behaviour can indicate us that, they use this technology and they are lover of this technology, for that reason they are using this technology.

\section{References}

[1] Sari, A. (2012) Impact of Determinants on Student Performance towards Information Communication Technology in Higher Education. International Journal of Learning and Development, 2, 18-30. http://dx.doi.org/10.5296/ijld.v2i2.1371

[2] Cellatoğlu, N. and Sari, A. (2010) Environmental Impacts of Private Transportation on Sustainable Development: A Case Study of Northern Cyprus. 1st International Sustainable Building Symposium, Volume 1, 441-445.

[3] Sari, A., Karaduman, A. and Firat, A. (2015) Deployment Challenges of Offshore Renewable Energy Systems for Sustainability in Developing Countries. Journal of Geographic Information System, 7, 465-477. http://dx.doi.org/10.4236/jgis.2015.75037

[4] Sari, A. (2014) Economic Impact of Higher Education Institutions in a Small Island: A Case of TRNC. Global Journal of Sociology, 4, 41-45.

[5] Sari, A. (2012) Diversification of Tourism Activities in Small Island Developing States. International Journal of Applied Science and Technology, 2.

[6] Yankee Group Research, Mobile User Survey Results Part 1: Will Next Generation Data Services Close the Value Gap? 2002.

[7] Instat/MDR. Worldwide Wireless Data/Internet Market: Bright Spots in a Dark Industry. 2002.

[8] Ghosh, A.K. and Swaminatha, T.M. (2001) Software Security and Privacy Risks in Mobile e-Commerce. Communications of the ACM, 44, 51-57. http://dx.doi.org/10.1145/359205.359227

[9] Tarasewich, P. (2003) Designing Mobile Commerce Applications. Communications of the ACM, 46, 57-60. http://dx.doi.org/10.1145/953460.953489

[10] Will, G. (2004) Upstart Airline Shows Direction of Industry. The Chicago Sun-Times, Chicago Sun Times Inc., Chicago. http://web.lexis-nexis.com

[11] Tsalgatidou, A., Veijalainen, J. and Pitoura, E. (2000) Challenges in Mobile Electronic Commerce. Proceedings of IEC 
of the Third International Conference on Innovation through E-Commerce, Manchester, 14-16.

[12] Turban, E. (2004) Electronic Commerce: A Managerial Prospective. Pearson Education, Inc., Upper Saddle River.

[13] Boon, S. and Holmes, J. (1991) The Dynamics of Interpersonal Trust: Resolving Uncertainity in the Face of Risk. In: Hinde, R. and Gorebel, J., Eds., Cooperation and Prosocial Behaviour, Cambridge University Press, Cambridge, 190-211.

[14] Ambrose, P. and Johnson, G. (2000) A Trust Based Model of Buying Behavior in Electronic Retailing. Proceedings of America Conference of Information System.

[15] Hoffman, D., Novak, T. and Peralta, M. (1999) Building Customer Trust Online. Communications of ACM, 42, 54-57. http://dx.doi.org/10.1145/299157.299175

[16] Ratnasingham, P. and Kumar, K. (2000) Trading Partner Trust in Electronic Commerce Participation. Proceedings of International Conference of Information Systems.

[17] Cheung, C. and Lee, M. (2000) Trust in Internet shopping: A Proposed Model and Measurement Instrument. Proceedings of America Conference of Information System.

[18] Androulidakis, N. and Androulidakis, I. (2005) Perspectives of Mobile Advertising in Greek Market. Proceedings of 2005 International Conference on Mobile Business (ICBM 2005). http://dx.doi.org/10.1109/icmb.2005.78

[19] Thornhill, A., et al. (2003) Research Methods for Business Students. 3rd Edition, Rotolito Lombarda, Italy, $72,85$.

[20] Robson, C. (1993) Real World Research. A Resource for Social Scientists and Practitioner Researchers. Blackwell Publishers Inc., Oxford. 